\title{
A importância de Florestan Fernandes na questão da escola pública atual
}

\section{The importance of Florestan Fernandes in the present public- school issue}

\author{
Jaime Ernesto Winter Hughes León \\ Instituto de Economia (IE), Universidade Federal do Rio de Janeiro (UFRJ) \\ jaime.leon@ie.ufrj.br \\ orcid.org/0000-0001-8400-2801 \\ Maria Mello de Malta \\ Instituto de Economia (IE), Universidade Federal do Rio de Janeiro (UFRJ) \\ mariammalta@yahoo.com.br \\ orcid.org/0000-0002-5538-940X
}

Resumo. Defendemos que a luta pela escola pública tem contornos específicos no capitalismo dependente. Seguindo a linha de defesa de um autor fundamental desta pauta no Brasil, Florestan Fernandes, fazemos uma análise interdisciplinar de história do pensamento socioeconômico brasileiro sobre educação pública brasileira, a partir da conformação de uma peculiar revolução burguesa no Brasil durante o século XX, para demonstrar a importância deste debate atualmente. $\mathrm{O}$ artigo se mostra urgente na medida em que os desafios de nossa formação seguem válidos, no sentido de a extrema segregação social persistir no país. Além disso, no atual momento, o governo está atacando ideologicamente a autonomia universitária e, por meio da política econômica, enfraquecendo a educação pública em favorecimento da educação privada.

Palavras-chave: Escola Pública. Capitalismo dependente. Democracia

Abstract. We argue that the struggle for the public-school has specific boundaries within the dependent capitalism. Following a line of defense proposed by a fundamental author of this agenda in Brazil, Florestan Fernandes, we make an interdisciplinary analysis of the history of Brazilian socioeconomic thought in the Brazilian public education, based on the formation of a peculiar bourgeois 
revolution in Brazil during the 20th century, to show the importance of this debate today. The article is urgent on the grounds that the challenges of our formation are still valid, as the extreme social segregation in the country lingers on. Besides, at the present time, the government is ideologically attacking thew university autonomy, and, through economic policy, it is weakening the public education in favor of private education.

Keywords: Public-school. Dependent capitalism. Democracy.

Recebido: 01/10/2018 Aceito: 27/10/2018 Publicado: 05/11/2018

\section{Introdução}

Vivemos uma crise estrutural do capital, desde a disseminação do neoliberalismo no fim da década de 1970, como a forma ideológica que preza pela liberdade dos indivíduos, pela redução do Estado na intervenção socioeconômica e que reúne políticas econômicas que favorecem o capital em detrimento dos direitos trabalhistas e sociais e da sustentabilidade do meio ambiente. A pandemia do novo coronavírus exponenciou esta crise socioeconômica. Em especial, a educação vem sofrendo os efeitos desta crise estrutural que, consequentemente, foram intensificadas com a chegada da pandemia. Desde o governo de Michel Temer, promove-se a aceleração do sucateamento da educação pública. O "Teto dos Gastos", que estabeleceu o teto para os gastos públicos em termos reais por 20 anos, está promovendo uma redução drástica dos dispêndios com educação no país. O contingenciamento das verbas para o Conselho Nacional de Desenvolvimento Científico e Tecnológico (CNPq) é evidência do descaso com o futuro da educação e da produção de uma ciência autônoma no país.

Entendemos que este cenário não é aleatório e episódico, mas fruto de um processo histórico que estabeleceu um padrão de acumulação e dominação burguês consolidado com a revolução burguesa neste país de capitalismo dependente, conforme nos apresenta Leher (2018). Desta forma, a defesa da escola pública no Brasil e na América Latina segue sendo mais um dos desafios do capitalismo dependente latino-americano. Pode-se afirmar que esta bandeira está na ordem do dia na região pelo menos desde o período de transição em que as sociedades latino-americanas iniciavam seu ciclo na ordem social competitiva como sociedades de classes capitalistas.

Um ponto de inflexão importante para esta luta, nestas sociedades americanas ao sul do trópico de câncer, foi a Reforma de Córdoba em 1918 na Argentina. Este foi o primeiro movimento significativo de contestação do modelo de ensino europeu na região, que colocava uma característica típica ao capitalismo dependente em evidência: o elevado grau de resistência às mudanças sociais das classes dominantes burguesas. Durante o movimento argentino foram contestados o papel da autoridade universitária e o papel do 
ensino; a falta de participação dos estudantes e servidores na gestão universitária, restrita a um pequeno grupo de docentes catedráticos, e os mecanismos que impediam a universidade exercer seu papel enquanto instrumento de produção do ensino, da pesquisa e da extensão e como meio de promover o desenvolvimento científico e com ele o desenvolvimento socioeconômico.

A luta pela Escola Pública no Brasil é parte daquele movimento, no entanto merece ser compreendida também em suas particularidades. A contribuição do militante, sociólogo, publicista e educador Florestan Fernandes nos tocou como essencial para tal compreensão, mas não porque o autor tenha sido professor catedrático de Sociologia I da Universidade de São Paulo, mas porque foi uma das mais importantes figuras na defesa da educação pública, laica e unitária no país. Dois momentos de sua atuação merecem destaque: o primeiro foi durante a elaboração da Lei de Diretrizes e Bases na década de 1960; o segundo foi entre a Constituinte de 1987 e até o fim do seu mandato como deputado federal em 1995.

Iremos, através de um trabalho interdisciplinar de história do pensamento socioeconômico brasileiro, demonstrar a importância da contribuição de Florestan Fernandes na compreensão do papel da escola pública no Brasil atual. Neste sentido, apontamos que o trabalho de Fernandes é fundamental por mostrar os limites e desafios do uso da educação como fator de transformação social na formação brasileira. Além de textos da obra de Florestan, usaremos alguns intérpretes de sua obra e pesquisadores da área de educação como Saviani (1996), Leher (2012, 2018), León (2019), e Accioly para atualizar o debate.

\section{Educação pública e capitalismo dependente?}

Para Leher (2012), a obra de Florestan Fernandes apresenta um método que é um verdadeiro processo contínuo de retificação e de elaboração de novas sínteses do que é a sociedade de classes latino-americana. Em especial, nos detemos na formulação do sociólogo paulistano de que a sociedade de classes brasileira além de ter um componente de "demora cultural" representado pela resistência intensa à mudança dos círculos conservantistas do país, é marcada indelevelmente pela categoria de capitalismo dependente, um tipo de capitalismo específico e diferente das formações sociais burguesas de tipo europeu (LEÓN, 2019). Florestan afirma que nossas sociedades encarnam uma situação específica, segundo ele:

que só pode ser caracterizada através de uma economia de mercado capitalista duplamente polarizada, destituída de autossuficiência e possuidora, no máximo, de uma autonomia limitada. [...] Nos planos da estrutura, funcionamento e diferenciação do sistema econômico, a dupla polarização do mercado suscita uma realidade nova e inconfundível (FERNANDES, 1968, p. 36) 
Assim, a incapacidade de autossuficiência dos países latino-americanos e o elevado nível de segregação social interna conformam a dupla articulação do capitalismo dependente e uma "democracia restrita" (FERNANDES, 1968). A formação-social específica do Brasil, em particular, e da América Latina, em geral, é, para Florestan Fernandes, fruto da forma peculiar que se desenrolou o processo de revolução burguesa na região. Na transição da ordem social neocolonial para a sociedade de competitiva de classes (período entre meados do século XIX e início do século XX), o processo revolucionário burguês latino-americano do século XIX ocorreu de forma distinta dos casos tidos como clássicos na Inglaterra, nos Estados Unidos e na França dos séculos XVII e XVIII, pois diferentemente daqueles movimentos a revolução burguesa dependente não precisou separar os interesses das antigas classes dominantes dos interesses das burguesias ascendentes. Pelo contrário, na América Latina as burguesias dependentes provieram das oligarquias do período colonial e neocolonial e, justamente por isso, lograram conciliar opressão, repressão e cooptação dos trabalhadores como seu padrão de acumulação e dominação (LEÓN, 2019).

A formulação sobre a revolução burguesa brasileira, e de sua subsequente consolidação com a contrarrevolução preventiva advinda com o golpe civil-militar de 1964, é o ápice da interpretação de Florestan Fernandes sobre o capitalismo dependente. Leher (2012) aponta que foi através da categoria de capitalismo dependente e da percepção da rigidez às mudanças sociais das classes dominantes que o sociólogo paulista conseguiu evidenciar as barreiras impostas à existência de uma reforma educacional de caráter democrático e republicano. Por este mesmo motivo o autor acabou por elaborar uma interpretação que buscasse a solução da questão da educação no Brasil por fora da ordem burguesa.

\section{Florestan Fernandes e a educação pública.}

Florestan Fernandes esteve engajado com esta bandeira desde sua militância no Partido Socialista Revolucionário, de orientação trotskista, no começo da década de 1940 até o fim de sua vida em 1995 (SAVIANI, 1996). Neste período, pode-se destacar duas fases marcantes e complementares: i) a de defesa da escola pública em decorrência da Lei de Diretrizes e Bases no começo da década de 1960 e ii) o de sua atuação no Congresso Nacional, para o qual foi eleito em 1986 e reeleito em 1990. Vale frisar, como destacado acima, que estes momentos não são independentes entre si, a militância pela educação pública de Florestan Fernandes foi um processo contínuo de elaboração de textos e documentos e de organização de atos pela educação pública.

Entre as duas fases o autor foi aposentado compulsoriamente da Universidade de São Paulo pelos efeitos do Ato Institucional número 5 de 1968 (AI-5) e se exilou, período no qual elaborou o conceito de capitalismo dependente em "Sociedade de Classes e Subdesenvolvimento" (FERNANDES, 1968), concluiu sua análise sobre o processo de 
revolução burguesa no Brasil em "A revolução burguesa no Brasil: ensaio de interpretação sociológica" (FERNANDES, 1975a) e publicou o livro "Circuito fechado: quatro ensaios sobre o poder institucional" (FERNANDES, 1976), onde complementa a interpretação apresentada na obra sobre a revolução burguesa no Brasil, introduzindo a questão do negro e da educação de forma mais desenvolvida.

Na primeira fase, iniciada em 1959 com a "Campanha em defesa escola pública" e que girava em torno da aprovação do projeto de lei de Diretrizes e Bases (LDB) da Educação Nacional, o papel militante de Florestan Fernandes se destacou de sua atuação enquanto acadêmico. Segundo ele, "os segmentos da sociedade civil que são capazes de agir organizadamente em defesa de seus interesses e valores sociais [...] são as camadas dominantes" (FERNANDES, 1966, p.362). Para o intelectual os setores dominantes impediram qualquer aspiração liberal e republicana de reforma educacional preconizada pelo projeto LDB Clemente Mariani. Os interesses das instituições particulares e do clero católico alteraram o projeto de lei de tal maneira que as aspirações de "civilizar a sociedade civil" dos pioneiros da "educação nova" se viram frustradas.

Saviani (1996) e Leher (2012) concordam que, no começo da década de 1960, Florestan Fernandes era o principal expoente da campanha, mas que não havia consenso entre os diferentes grupos que reivindicavam a defesa da Escola Pública.

Eram três os movimentos que conformavam esta empreitada: i) os socialistas guiados por Florestan e outros intelectuais como Octávio Ianni, Fernando Henrique Cardoso e Wilson Cantoni; ii) os liberais pragmatistas, que teriam sua origem no movimento da Escola Nova (movimento da década de 1930 no Brasil em defesa da escola pública, laica e gratuita) e que era puxado por Anísio Teixeira, Fernando de Azevedo, Lourenço filho e outros e iii) os liberais idealistas liderados por professores ligados à Universidade de São Paulo e conectados ao jornal O Estado de São Paulo como Roque Spencer Maciel de Barros e Laerte Ramos de Carvalho, João Villalobos e o diretor e proprietário do jornal, Júlio de Mesquita Filho.

Segundo Leher (2012) as ideias-força dos grupos eram marcadamente diferentes. Os socialistas enxergavam a educação como um instrumento para a superação do subdesenvolvimento econômico, social, político, cultural e social da sociedade brasileira; já os liberais idealistas pregavam uma ideia essencialista do homem, portanto para eles a educação deveria ter como proposta a afirmação da liberdade, originalidade e autonomia ética do indivíduo; por fim, os liberais pragmatistas tinham argumentos de ordem prática, portanto para eles a escola pública devia ser defendida por sua maior eficiência diante das necessidades postas pela sociedade da época.

Desta configuração de grupos em torno da defesa da escola pública, o grupo que detinha a hegemonia do movimento era o de Júlio de Mesquita, por ser ele detentor de um importante aparelho privado de hegemonia, nominalmente um dos jornais mais importantes à época. Tendo contribuído para a inclusão dos sindicatos nas discussões e 
organizado a I Convenção Operária em Defesa da Escola Pública em 1961, Florestan Fernandes reconhecia que a Campanha, no geral, estava sob hegemonia liberal.

O projeto sobre a lei de Diretrizes e Bases foi aprovado como a lei n. 4024/1961. Para o sociólogo, a lei aprovada era um verdadeiro Cavalo de Troia dos interesses privatistas no seio do poder Executivo. O balanço da campanha, na perspectiva do próprio Florestan, foi de ter viabilizado o seu contato com vários setores da sociedade (jornalistas, educadores, estudantes, elites tradicionais, líderes sindicais, representantes de movimentos religiosos) e ter lhe mostrado o quadro desanimador das possibilidades de mudança social. Segundo palavras do autor, tal quadro era o seguinte: as debilidades das correntes radical-democráticas; as deficiências do movimento socialista; a violência e o obscurantismo da reação conservadora; a neutralização do Legislativo e do Executivo por interesses particularistas regionais ou de classe e setoriais, todos fundamentalmente egoístas e antinacionais; uma persistente "reação sociopática à mudança social”, que submetia todas as inovações de significado político ao mais cruel e cego controle de classe (FERNANDES, 1977).

Após esta Campanha, Florestan Fernandes também participou ativamente da ação política na época da reforma universitária entre 1964 e 1969, mesmo após ter sido aposentado compulsoriamente pelos efeitos do AI-5 de 1968. Porém foi a partir de 1987, após ter sido eleito em 1986 para a Assembleia Constituinte, que o autor colocou a questão da educação no centro do que trataria nas discussões para a nova carta magna para o país. De fato, no que toca à educação o militante foi ativo na discussão do capítulo sobre educação da nova constituição e nas reflexões sobre o projeto de uma nova lei de Diretrizes e Bases da Educação Nacional.

Uma diferença marcante desta segunda campanha por uma nova Lei de Diretrizes e Bases da década de 1980 em relação à campanha de princípios dos anos 1960 foi a percepção de que a luta dos trabalhadores em geral e a luta dos trabalhadores da educação em particular seria determinante para o futuro da nova lei. Reconhecendo a necessidade deste protagonismo dos trabalhadores da educação, Florestan se dedicou ao papel de publicista da educação pública tendo divulgado uma série de títulos acerca do tema e sua percepção madura de que a questão democrática brasileira perpassa uma função ativa dos "de baixo" na ação transformadora da sociedade.

Não por acaso, Florestan associava o começo de uma verdadeira democracia no Brasil a partir do momento em que os problemas dos negros, dos indígenas e mais pobres da população brasileira começassem a ser resolvidos. Dentre os livros mais importantes sobre o tema está "O desafio educacional" (FERNANDES, 1989) que é uma coletânea de textos sobre a erupção de análises e debates sobre o tema e que, para o autor, apontam na direção da necessidade de uma verdadeira revolução da educação que colocasse os oprimidos no interior da rede escolar reconhecendo, porém, que o desafio socialista para a educação ainda era pautado pela utilidade das reformas burguesas da educação (LEHER, 2012). Os "de baixo" não podem, segundo o autor, abrir mão de conquistas dentro da ordem, desde que não percam de vista que o objetivo estratégico da solução se 
dá por fora da ordem burguesa. Daí a proposição de que seria crucial que o educador pudesse ser reeducado na ótica da classe trabalhadora, pois enquanto sujeito pertencente a classe poderia perceber as necessidades culturais desta classe. Leher (2012) nos traz uma importante reflexão sobre este ponto:

\begin{abstract}
Diante do conflito entre os interesses dos representantes do ensino privado e do ensino público, Florestan Fernandes diagnosticou que o Estado deveria gozar de autonomia para estruturar a educação pública, mas sendo ele uma instituição de classe, orientada pelos interesses particularistas, egoístas e antinacionais das frações burguesas, pende para o lado das instituições privadas. A ideia de um Estado educador era vista pelo autor com cuidado, pois sabia ser necessário que houvesse a democratização do poder e da riqueza e que fosse impedido que houvesse o monopólio de poder nas mãos de pequenos grupos. Seu ideal era de uma escola com autonomia relativa reforçada se baseava na defesa de uma autonomia que estivesse dialeticamente relacionada com a independência econômica, a emancipação nacional e com a revolução democrática (LEHER, 2012).
\end{abstract}

A avaliação de Florestan sobre o capítulo da educação da Constituição de 1988 foi que o peso do poder da Igreja católica, em sua feição mais reacionária e obscurantista, e da bancada privatista, abrigada no "centrão", um agregado de parlamentares a serviço de quem realmente comandou a Constituinte - "capital estrangeiro, capital nacional, Estado plutocrático" - impôs retrocessos importantes nos dispositivos educacionais da Carta, como a admissão de verbas públicas para as instituições privadas (art. 213), possibilitando o ensino religioso nas escolas públicas (art. 210), e registrando que "o ensino é livre à iniciativa privada" (FERNANDES, 1989b, p.121).

\title{
4. Conclusões
}

No já referido artigo de Leher (2012), aparece uma percepção que nos parece totalmente válida hoje de que atualmente o cenário não é muito distinto, se não pior. Os setores privatistas são beneficiados por meio de fundos de investimentos multinacionais, os quais promovem a concentração e centralização da educação superior privada. Além disso, a série de incentivos fiscais para as instituições privadas e a promoção da financeirização do consumo e do ensino como nos casos do Programa Universidade Para Todos, criado em 2004, e do Fundo de Financiamento Estudantil em 1999, promovem a difusão de instituições puramente mercantis preocupadas somente com seu horizonte de curto prazo de lucratividade e não com a educação como um meio para o desenvolvimento socioeconômico. No Brasil, é destacada a ação do grupo Kroton-Anhanguera, maior monopólio do mundo no setor de ensino que se beneficiou das ações dos anos de governo do Partido dos Trabalhadores aumentando exponencialmente sua lucratividade. 
Após o impeachment da presidente Dilma Rousseff, a orientação da educação em favorecimento dos interesses do setor privado foi intensificada no governo de Michel Temer e agora essa política ganha facetas ainda mais radicalizadas nas ações do governo Bolsonaro, sob as ações radicalmente ideológicas do Ministério da Educação. Vale destacar que desde a campanha eleitoral do atual presidente, se afirma a inadequação da existência de educação superior pública, argumentando que há disputa entre recursos para a educação superior e a educação básica, o que revela uma incapacidade de enxergar a educação pública como um sistema integrado, portanto, unitário. Agregado a isso endossa a reforma tecnicista e reducionista do Ensino Médio proposta em 2018 e chega a propor a educação básica a distância e que agora, sob os efeitos da crise socioeconômica exponenciada pelo novo coronavírus, se expande para todos setores da educação até chegar ao ensino superior.

Sob o governo Bolsonaro, tem-se um quadro que além do reforço das políticas neoliberais e orientação de esvaziamento da educação pública em favorecimento do setor privado, há um ataque fortemente ideológico institucionalizado vindo tanto do Ministério da Educação quanto da presidência na forma de difamação da vida da comunidade acadêmica. O projeto "Future-se", que acelera a tendência de mercantilização da educação pública sob a maquiagem da "autonomia financeira", promove a cobrança de mensalidades, libera o uso de prédios públicos por empresas privadas e diminui o investimento público em educação, desmonta um serviço público fundamental na medida em que as Instituições Federais de Ensino Superior teriam que captar recursos a partir de fontes externas. Este projeto está sendo encaminhado nos bastidores durante a atual pandemia.

Na semana em que este texto foi finalizado, foi assinada uma medida provisória (MP) 979 de 2020 que representa claro ataque à autonomia universitária, prevista na constituição federal, ao permitir a nomeação direta de reitores e vice-reitores das universidades federais, institutos federais e o Colégio Pedro II pelo governo durante o período de pandemia. Segundo a MP, as nomeações serão sem consulta à comunidade acadêmica e sem formação de lista tríplice. Vale lembrar que em 2019, já havia sido feito um movimento neste sentido com a MP 914 de 2019, mas que foi barrada pelo Congresso Nacional.

Em virtude deste quadro conjuntural de ataques ideológicos e de política econômica e do quadro estrutural de capitalismo dependente e seus dilemas a resolver, afirmamos que a contribuição de Florestan Fernandes sobre a luta da escola pública segue muito atual para qualquer possibilidade de transformação social. O Estado brasileiro vem promovendo, de acordo com os interesses do neoliberalismo, mudanças que na verdade impedem uma verdadeira transformação social no sentido de integrar a maioria da população neste Estado, confirmando aquilo que Florestan Fernandes chamara de resistência sociopática às mudanças sociais. 


\section{Referências}

ACCIOLY, I. The Attacks on the Legacy of Paulo Freire in Brazil: Why He Still Disturbs so Many? In Macrine S. (org.) Critical Pedagogy in Uncertain Times: Education, Politics and Public Life. Londres: Palgrave Macmillan, Cham, 2020. P.117-138.

FERNANDES, F. Educação e sociedade no Brasil. São Paulo: Dominus; Edusp, 1966.

FERNANDES, F. Sociedade de classes e subdesenvolvimento. Rio de Janeiro: Zahar Editores, 1968 [1981a].

FERNANDES, F. A revolução Burguesa no Brasil: Ensaio de interpretação Sociológica. São Paulo: Editora Globo, 1975 [2011].

FERNANDES, F. A universidade brasileira: reforma ou revolução? São Paulo: AlfaÔmega, 1975.

FERNANDES, F. O desafio educacional. São Paulo: Cortez, 1989a.

FERNANDES, F. A Constituição inacabada, vias históricas e significado. São Paulo: Estação Liberdade, 1989b.

LEHER, R. Florestan Fernandes e a Defesa da Educação Pública. Educação e Sociedade, Campinas, v. 33, n. 121, p. 1157-1173, 2012.

LEHER, R. Universidade e heteronomia cultural no capitalismo dependente? Um estudo a partir de Florestan Fernandes. Rio de Janeiro: Consequencia. 2018.

LEÓN, J. E. W. H. Resistência às mudanças sociais: uma visão crítica da democracia brasileira. Tese (Doutorado em Economia) - Instituto de Economia, Universidade Federal do Rio de Janeiro, Rio de Janeiro, 2019.

SAVIANI, D. Florestan Fernandes e a Educação. Estudo Avançados, São Paulo v.10, n. 26, 1996, p. 71-87. 